\title{
Low potassium intake and its association with blood pressure among adults in Malaysia: findings from the MyCoSS (Malaysian Community Salt Survey)
}

Lalitha Palaniveloo ${ }^{1 *}$, Rashidah Ambak', Fatimah Othman', Nor Azian Mohd Zaki², Azli Baharudin?', Nur Shahida Abdul Aziz and Ruhaya Salleh ${ }^{1}$

\begin{abstract}
Background: High blood pressure or hypertension is well recognized as an important modifiable risk factor for cardiovascular diseases. Several studies had indicated potassium intake has a blood pressure lowering effect. This study aimed to estimate potassium intake via 24-h urinary potassium excretion and to determine the association between potassium intake and blood pressure among adults in Malaysia.

Methods: Data for 424 respondents in this study were drawn from MyCoSS, a nationwide cross- sectional study conducted among Malaysians who were 18 years and above. Respondents were recruited using stratified cluster sampling, covering urban and rural areas in each state in Malaysia. Data collection was undertaken from October 2017 until March 2018. A single urine sample was collected over $24 \mathrm{~h}$ for quantification of potassium excreted. Information on socio-demography and medical history of the respondents were collected by intervieweradministered questionnaires. Anthropometric measurements were measured using validated equipment. BMI was estimated using measured body weight and height. Digital blood pressure monitor (Omron HBP-1300) was used to measure blood pressure. Descriptive statistics, analysis of variance (ANOVA), and multivariable linear regression were used to analyze the data in SPSS Version 21.

Results: Mean 24-h urinary potassium excretion for the 424 respondents was $37 \mathrm{mmol}(95 \% \mathrm{Cl} 36,38)$. Gender and ethnicity showed statistically significant associations with 24-h urinary potassium excretion. However, potassium excretion was not significantly associated with blood pressure in this study.

Conclusion: Potassium intake is very low among the adults in Malaysia. Therefore, further education and promotional campaigns regarding daily consumption of potassium-rich diet and its benefits to health need to be tailored for the Malaysian adult population.
\end{abstract}

Keywords: Potassium, Adults, Blood pressure, Malaysia

\footnotetext{
* Correspondence: lalitha.p@moh.gov.my

${ }^{1}$ Institute for Public Health, National Institutes of Health, Ministry of Health Malaysia, Selangor, Malaysia

Full list of author information is available at the end of the article
} 


\section{Background}

Nearly 1 billion people in the world are affected by high blood pressure or hypertension and it is recognized as an important modifiable risk factor for cardiovascular diseases. High blood pressure affects one out of three adults in South-East Asian countries, a condition identified to be the leading cause for an estimation of 1.5 million deaths in those countries [1]. In 2015, the prevalence of hypertension was $30.3 \%$ among adults who were 18 years old and above in Malaysia [2]. World Health Organization (WHO) in their report Global Atlas on Cardiovascular Disease Prevention and Control (2011) had stated that WHO African region recorded the highest prevalence of high blood pressure among their adults with $46 \%$ while the lowest was in WHO Americas region with $35 \%$ [3].

Various factors such as unhealthy dietary practices, smoking, obesity, and physical inactivity affect blood pressure [4]. With regard to potassium, this mineral is important for maintaining total body fluid, nerve impulses transmission, heart beat (rhythm) maintenance, and muscle contractions $[5,6]$. High potassium intake also has been associated with blood pressure lowering effect among those with elevated blood pressure, reducing cardiovascular-related mortality, preventing or slowing down the advancement of renal disease and lowering urinary calcium excretion, thereby, reducing the risk of osteoporosis [7, 8]. In addition, increased potassium intake alleviates the negative effects of high sodium consumption on blood pressure $[9,10]$. A possible mechanism for potassium's effect on blood pressure is explained by its role in increasing the amount of sodium excreted via urine, which in return, reduces the availability of sodium in the body. This will lead to relaxation of vascular smooth muscles, thus lowering the blood pressure [10]. These findings on the protective effects of potassium intake led to the WHO recommendation of a daily potassium intake of $90 \mathrm{mmol}(3510 \mathrm{mg})$ for adults [11]. However, the 2017 Malaysian Recommended Nutrient Intake (RNI) for potassium for adults > 18 years old is slightly higher at $120 \mathrm{mmol}(4700 \mathrm{mg}$ ) per day [12]. This is in line with the Institute of Medicine's (IOM) recommendation on adequate daily potassium intake for adults [13].

Estimating potassium intake via potassium excreted in 24-h urine samples is a very reliable method in comparison with dietary assessment. Potassium is excreted from the body through urine (90\%), stool (10\%) and sweat (very little) [14]. Conversely, estimation of potassium intake through dietary assessment is prone for recall bias from the respondents which can lead to under or over estimation of the nutrient intake [15].

Currently, Malaysia has very limited data regarding potassium intake. The only data available is for adolescents which was determined through dietary intake [16]. Moreover, studies conducted worldwide showed mixed views on association between potassium intake and blood pressure $[9,10,17-20]$. In view of this and the steady increase in prevalence of hypertension among the adults, there is an urgent need for baseline data on potassium intake in Malaysia. Therefore, this study aimed to estimate potassium intake via 24-h urinary potassium excretion among adults in Malaysia. A secondary aim was to assess the relationship between potassium intake and blood pressure.

\section{Methods}

Data for this study were drawn from MyCoSS, which was a nationwide cross-sectional study targeting Malaysian adults who were 18 years and above who lived in non-institutional living quarters (LQ). The sample size was calculated using a formula for estimating mean, using the mean 24-h urinary potassium excretion value obtained from MySalt Study (2012) of $35.57 \mathrm{mmol} / \mathrm{L}$ (17.12) [Institute for Public Health. Determination of Dietary Sodium Intake among the Ministry of Health Staff (MySalt 2012). Ministry of Health, Malaysia. 2012 (Unpublished)], precision between 4 and 12, estimated design effect of 1.5 and with consideration of $60 \%$ nonresponse rate. The respondents were recruited using stratified cluster sampling method, covering both urban and rural areas in each state in Malaysia. Data collection was undertaken from October 2017 until March 2018. Inclusion criteria was Malaysian adults who were 18 years old and above. Those who were fasting during data collection, on diuretic therapy $(<4$ weeks), in any situation which will results in difficulties for 24-h urine collection, pregnant, diagnosed with kidney disease, heart failure, or liver disease were excluded from this study.

\section{4-h urine collection}

Each participant was given detailed oral and printed instructions on collection of the 24-h urine accurately, together with a 5-L screw-capped plastic collection bottle, a urine collection jug, plastic carrier bags (for transporting the urine collection set), a safety pin (to be attached to undergarments, as a remainder for urine collection), and a poster. Respondents was advised to discard the first urine excreted in the morning and collected all urine throughout the 24-h duration. The last urine collected was the first urine excreted on the start of the second day. The respondents were required to record the timing of the first and last collection of 24-h urine. They were also required to inform the researcher on any missed urine collection. Urinary creatinine level and volume excreted were used as an indicator for completeness of urine collection. Samples were excluded if the urinary creatinine $<6 \mathrm{mmol} /$ day for men or $<4 \mathrm{mmol} /$ 
day for women, extreme outliers for urinary creatinine (i.e., > 3 SDs from the mean) or 24-h urine volume < $500 \mathrm{ml}$ for both genders. Samples from respondents who reported of missing urine collection between the 24-h time period were also excluded from the study.

The collected urine samples were brought to the nearest branch of the laboratory assigned at each study site. In that laboratory, the urine volume was measured and $30 \mathrm{ml}$ aliquot from each sample was preserved in a $4{ }^{\circ} \mathrm{C}$ refrigerator before being transported to the centralized laboratory in Shah Alam, Selangor, on the same day for analysis.

\section{Potassium measurement}

Potassium excreted in the urine was measured using indirect ion-selective electrode method [21]. An electric potential voltage is developed across the potassium membranes between the reference and the measuring electrode in accordance with the Nernst equation. The tension developed is then compared with the previously determined calibrator voltages and converted to an ion concentration [21]. Creatinine was measured according to Kinetic Jaffe (alkaline picrate with Lloyd's reagent) method. Both the analyses were conducted in the laboratory using Architect C machine (Abbott CI8200, IL, USA). The urinary samples were analyzed in duplicates and the coefficient of variation (CV) for potassium and creatinine were $12.2 \%$ and $5.5 \%$, respectively.

\section{Anthropometric measurement}

Digital weighing scale was used to measure body weight with an accuracy of $0.1 \mathrm{~kg}$ (TANITA HD-319, IL, USA). Stadiometer was used to measure height to the nearest $0.1 \mathrm{~cm}$ (SECA 213, CA, USA). An average of two measurements was recorded as the final reading for both parameters. Body mass index (BMI) was calculated by weight $(\mathrm{kg})$ divided by the square of height $\left(\mathrm{m}^{2}\right)$ and categorized according to WHO 2006 guidelines as follows: underweight $\left(\right.$ BMI $\left.<18.5 \mathrm{~kg} / \mathrm{m}^{2}\right)$; normal (BMI 18.5$24.9 \mathrm{~kg} / \mathrm{m}^{2}$ ); overweight (BMI $25.0-29.9 \mathrm{~kg} / \mathrm{m}^{2}$ ); and obese (BMI $\left.\geq 30 \mathrm{~kg} / \mathrm{m}^{2}\right)$.

\section{Blood pressure measurement}

Digital blood pressure monitor was used to measure blood pressure (Omron HBP-1300, Kyoto, Japan). The sensitivity and specificity of the Omron HBP-1300 used were $86.2 \%$ and $98.0 \%$, respectively. Blood pressure was measured in the morning during urine bottle collection from the participants' house. The participants were to be seated and asked to rest for at least $5 \mathrm{~min}$ before the measurement starts. The cuff used was wrapped to a tightness that allows two fingers to be inserted in between the cuff and the arm. The arm was placed at the same height as the heart during measurement. Three measurements with an interval of one to 2 min between each measurement were taken. The average of the last two readings was recorded.

\section{Socio-demographic information}

Interviewer administered questionnaire was used to gather information on medical history and sociodemographic factors: age, locality, race, education level, and household income.

\section{Statistical analysis}

All variables were described using descriptive statistics. Analysis of variance (ANOVA) was applied to compare mean urinary potassium excretion between the characteristics of the respondents. Multivariable linear regression was performed to determine the relationship between urinary potassium excretion level and blood pressure adjusted for covariates known to be associated with blood pressure including gender, ethnic, monthly household income, and BMI. Statistical significance was set at $p<0.05$. SPSS statistical software package version 21 was used for statistical analysis in this study (SPSS Inc., Chicago, IL, USA).

\section{Results}

A total of 424 respondents with urinary potassium excretion values were accepted for the analysis. The 24-h urinary potassium excretion of the respondents ranged between $25 \mathrm{mmol}$ and $122 \mathrm{mmol}$ with an overall mean of $37 \mathrm{mmol}$ (95\% CI 36, 38) (Fig. 1). Characteristics of the respondents are summarized in Table 1.

Table 2 shows the characteristics of the respondents by $24-h$ urinary potassium excretion. Men showed a significantly higher mean excretion of potassium $(39 \mathrm{mmol}$; 95\% CI 37, 40) compared with women ( $35 \mathrm{mmol}$; 95\% CI 34,38$)(p=0.003)$. Among the main ethnic groups, Malaysian Chinese had a significantly highest excretion of potassium with a mean of $42 \mathrm{mmol}(95 \%$ CI 37, 47) $(p=0.019)$ while the Malays had the lowest mean excretion, $36 \mathrm{mmol}$ (95\% CI 35, 37). Comparison by gender and ethnicity showed statistically significant associations with 24-h urinary potassium excretion while age, locality, monthly household income, and BMI of the respondents were not significantly associated.

This study shows there was no significant association between urinary potassium excretion and blood pressure. After adjusting for gender, age, and household income, there was a reduction of $0.15 \mathrm{mmHg}(95 \% \mathrm{CI}-$ $0.309,0.004 ; p=0.09)$ in systolic blood pressure, and a $0.12-\mathrm{mmHg}(95 \% \mathrm{CI}-0.219,-0.016 ; p=0.101)$ reduction in diastolic blood pressure per mmol increment in potassium excretion. 


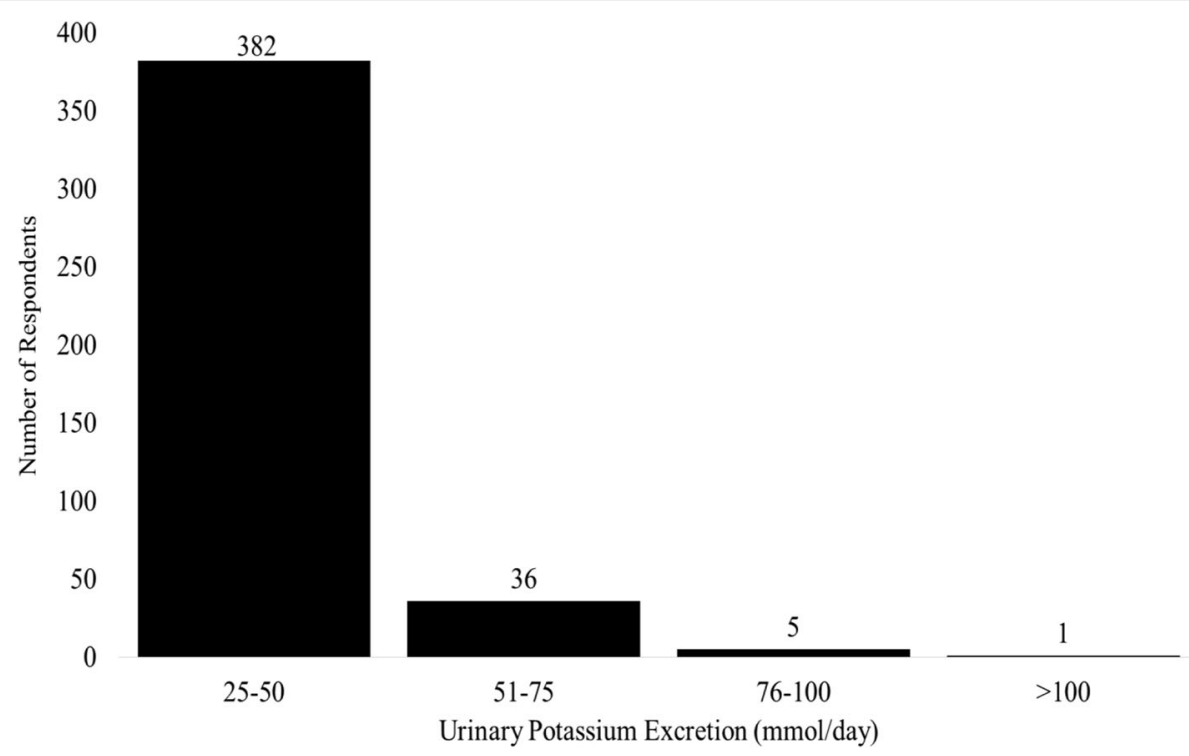

Fig. 1 Distribution of 24-h potassium excretion of the respondents $(n=424)$

\section{Discussion}

To date, this is the first study on 24-h urinary potassium excretion in Malaysia. Findings from this study serve as a proxy for daily potassium intake among the adults in Malaysia. Overall mean urinary potassium excretion of the respondents in this study was $37 \mathrm{mmol} /$ day which is lower than the recommended daily potassium intake by WHO (90 mmol), RNI for Malaysia, and IOM (120 mmol) [11-13]. It is also considerably lower compared to other reports. The Prospective Urban and Rural Epidemiological Study (PURE) involving 101,945 adults from 17 countries around the world reported mean urinary potassium excretion of $54 \mathrm{mmol} /$ day [22]. Likewise, National Health and Nutrition Examination Survey (NHANES 2014) reported mean urinary potassium excretion of $55 \mathrm{mmol} /$ day among adults aged between 20 and 69 years old in USA [23].

As expected, men had significantly higher mean excretion of potassium compared to women $(p=0.003)$. This result is similar to findings from Italy and West Africa respectively [24, 25]. Studies from China, Japan, and Iran showed mean urinary potassium excretion among men ranging between $40-50 \mathrm{mmol} /$ day and $40-42 \mathrm{mmol} /$ day among women $[17,26,27]$. This could be attributed by the fact that men generally require higher energy intake compared to women due to their larger body size. Consumption of higher caloric food will subsequently increase potassium intake as well $[25,28]$.

In this study, urinary potassium excretion was significantly different among the main ethnic groups in Malaysia with respondents from the Chinese ethnic group recorded the highest excretion level. There are no prior data available on potassium intake among the adults in Malaysia to compare with the findings from this study. However, data from the Malaysian Adult $\mathrm{Nu}-$ trition Survey (MANS) 2014 demonstrated that respondents of Chinese ethnicity had the highest frequency of fruits intake and second highest in frequency of vegetables intake among the ethnic groups in the country [29]. This could explain the reason of higher urinary potassium excretion demonstrated by the Malaysian Chinese in our study since vegetables and fruits are the two main contributors of potassium in the diet [30].

With regard to its relationship to blood pressure level, urinary potassium excretion was not a statistically significant predictor in our study. Studies conducted in China and Netherlands showed a similar finding $[18,19]$. However, findings from other studies have suggested urinary potassium excretion does affect blood pressure [9, 10, 17, 20]. It is possible that potassium's effect in reducing blood pressure occurs only when there is a high potassium intake $[10,18]$. In this case, the relationship may not be captured in the MyCoSS sample because $99 \%$ of the respondents had their mean urinary potassium excretion lower than the recommended daily intake by WHO (90 mmol) [11]. Despite the absence of statistical significance, our regression output does show a negative association of systolic $(\beta=-0.15 \mathrm{mmHg})$ and diastolic blood pressure ( $\beta=-0.12 \mathrm{mmHg}$ ) per $\mathrm{mmol}$ of potassium excretion.

MyCoSS being the first nationwide study to quantify sodium and potassium excretions using 24-h urine sample in the country is the main strength of this study. Findings from this study will serve as the baseline data on urinary potassium excretion among adults in Malaysia. Moreover, this study applied a reliable method in estimating intake of potassium among the population 
Table 1 Characteristics of the respondents by gender

\begin{tabular}{|c|c|c|c|}
\hline \multirow[t]{2}{*}{ Characteristic } & $\begin{array}{l}\text { Total } \\
(N=424)\end{array}$ & $\begin{array}{l}\text { Men } \\
(N=212)\end{array}$ & $\begin{array}{l}\text { Women } \\
(N=212)\end{array}$ \\
\hline & \multicolumn{3}{|c|}{ Mean $(95 \% \mathrm{Cl}) / n(\%)$} \\
\hline Age (years) & $49.1(47.2,50.9)$ & $50.0(47.7,52.4)$ & $47.7(45.3,50.2)$ \\
\hline$<40$ & $114(27.6)$ & $54(27.8)$ & $60(27.3)$ \\
\hline $40-60$ & $200(46.5)$ & $94(41.4)$ & $106(53.2)$ \\
\hline$>60$ & $110(25.9)$ & $64(30.8)$ & $46(19.5)$ \\
\hline \multicolumn{4}{|l|}{ Locality } \\
\hline Urban & $181(78.3)$ & $92(77.3)$ & 89 (79.6) \\
\hline Rural & $243(21.7)$ & $120(22.7)$ & $123(20.4)$ \\
\hline \multicolumn{4}{|l|}{ Ethnicity } \\
\hline Malay & $267(67.1)$ & $135(68.6)$ & $132(65.0)$ \\
\hline Chinese & $52(13.1)$ & $21(10.7)$ & $31(16.4)$ \\
\hline Indian & $19(7.9)$ & $7(6.1)$ & $12(10.4)$ \\
\hline Others & $86(11.9)$ & 49 (14.6) & $37(8.2)$ \\
\hline \multicolumn{4}{|l|}{ Education level } \\
\hline None & $28(3.2)$ & $13(3.0)$ & $15(3.4)$ \\
\hline Primary & $93(19.3)$ & $46(17.2)$ & $47(22.2)$ \\
\hline Secondary & $198(49.7)$ & $98(49.3)$ & $100(50.2)$ \\
\hline Tertiary & $105(27.8)$ & $55(30.5)$ & $50(24.3)$ \\
\hline Monthly household income (RM) ${ }^{a}$ & $\begin{array}{l}3888.5 \\
(3174.5,4602.6)\end{array}$ & $\begin{array}{l}3993.6 \\
(3206.8,4780.3)\end{array}$ & $\begin{array}{l}3749.2 \\
(2889.3,4609.0)\end{array}$ \\
\hline Low $(<3860)$ & $305(63.8)$ & $153(63.0)$ & $152(65.0)$ \\
\hline Middle (3860-8319) & $87(26.2)$ & $43(26.9)$ & $44(25.4)$ \\
\hline High ( $\geq 8320)$ & $32(9.9)$ & $16(10.1)$ & $16(9.6)$ \\
\hline Body mass index (BMI) $\left(\mathrm{kg} / \mathrm{m}^{2}\right)$ & $27.1(26.5,27.7)$ & $27.0(26.3,27.7)$ & $27.3(26.3,28.4)$ \\
\hline Underweight (< 18.5) & $10(1.8)$ & $5(2.2)$ & $5(1.3)$ \\
\hline Normal (18.5-24.9) & $140(33.9)$ & $69(30.4)$ & $71(38.5)$ \\
\hline Overweight (25.0-29.9) & $161(39.7)$ & $91(42.3)$ & $70(36.3)$ \\
\hline Obese $(\geq 30.0)$ & $113(24.6)$ & $47(25.2)$ & $66(23.8)$ \\
\hline \multicolumn{4}{|l|}{ Blood pressure $(\mathrm{mmHg})$} \\
\hline Systolic & $\begin{array}{l}136.0 \\
(133.5,138.4)\end{array}$ & $\begin{array}{l}136.7 \\
(133.6,139.9)\end{array}$ & $\begin{array}{l}134.9 \\
(131.1,138.7)\end{array}$ \\
\hline Dystolic & $81.8(80.5,83.0)$ & $82.88(81.0,84.8)$ & $80.3(78.4,82.1)$ \\
\hline 24-h urine volume (ml/day) & $\begin{array}{l}1654.2 \\
(1526.6,1781.7)\end{array}$ & $\begin{array}{l}1704.5 \\
(1548.2,1860.7)\end{array}$ & $\begin{array}{l}1587.5 \\
(1398.8,1776.2)\end{array}$ \\
\hline 24-h urinary creatinine (mg/day) & $\begin{array}{l}1171.8 \\
(1106.0,1237.5)\end{array}$ & $\begin{array}{l}1398.8 \\
(1323.2,1474.4)\end{array}$ & $\begin{array}{l}870.9 \\
(836.7,905.2)\end{array}$ \\
\hline
\end{tabular}

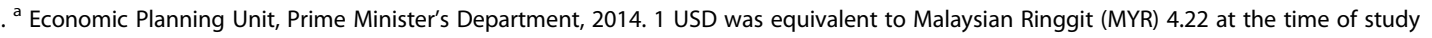

via 24-h urinary potassium excretion [14]. Few limitations were observed in this study. Firstly, potassium excretion was measured from a single 24-h urine. Data generated from a single 24-h urine analysis is insufficient to describe habitual intake of an individual but it can be a good indicator for average intake of a group of individuals [31]. This approach is acceptable because it is impractical to collect a few completed 24-h urine samples from all respondents in a nationwide study. Secondly, dietary intake of the respondents was not assessed accordingly to study the dietary pattern which causes a very low consumption of potassium-rich food. Data from MANS 2014 showed mean serving size of fruits among the adults was 1.40 servings/day compared to 2.00 servings/day as recommended in Malaysian Dietary Guideline (MDG) 2010. For vegetables, the mean serving size was 1.51 servings/ day compared to 3.00 servings/ day as recommended in MDG 2010 [12]. This shows Malaysians indeed were consuming 
Table 2 Characteristics of the respondents by 24-h urinary potassium excretion

\begin{tabular}{|c|c|c|c|}
\hline \multirow[t]{2}{*}{ Characteristic } & \multirow[t]{2}{*}{$n$} & \multicolumn{2}{|c|}{ Potassium (mmol/24 h) } \\
\hline & & Mean $(95 \% \mathrm{Cl})$ & $p$ value \\
\hline \multicolumn{4}{|l|}{ Gender } \\
\hline Men & 212 & $39(37,40)$ & \multirow[t]{2}{*}{$0.003^{*}$} \\
\hline Women & 212 & $35(34,38)$ & \\
\hline \multicolumn{4}{|l|}{ Age (years) } \\
\hline$<40$ & 114 & $35(33,37)$ & \multirow[t]{3}{*}{0.145} \\
\hline $40-60$ & 200 & $38(36,40)$ & \\
\hline$>60$ & 110 & $37(35,40)$ & \\
\hline \multicolumn{4}{|l|}{ Locality } \\
\hline Urban & 181 & $36(35,38)$ & \multirow[t]{2}{*}{0.349} \\
\hline Rural & 243 & $37(36,39)$ & \\
\hline \multicolumn{4}{|l|}{ Ethnicity } \\
\hline Malay & 267 & $36(35,37)$ & \multirow[t]{4}{*}{$0.019^{*}$} \\
\hline Chinese & 52 & $42(37,47)$ & \\
\hline Indian & 19 & $38(33,43)$ & \\
\hline Others & 86 & $37(35,39)$ & \\
\hline \multicolumn{4}{|c|}{ Monthly household income (RM) } \\
\hline Low $(<3860)$ & 305 & $36(35,38)$ & \multirow[t]{3}{*}{0.287} \\
\hline Middle (3860-8319) & 87 & $38(35,41)$ & \\
\hline High ( $\geq 8320)$ & 32 & $39(34,44)$ & \\
\hline \multicolumn{4}{|c|}{ Body mass index (BMI) $\left(\mathrm{kg} / \mathrm{m}^{2}\right)$} \\
\hline Underweight (< 18.5) & 10 & $34(24,44)$ & \\
\hline Normal (18.5-24.9) & 140 & $37(35,39)$ & \multirow{3}{*}{0.634} \\
\hline Overweight (25.0-29.9) & 161 & $36(34,38)$ & \\
\hline Obese $(\geq 30.0)$ & 113 & $38(36,40)$ & \\
\hline
\end{tabular}

very low amount of potassium-rich food. Lastly, intake of anti-hypertensive drugs was not included as one of the covariates to be controlled for in multivariable linear analysis to determine the relationship between blood pressure and urinary potassium excretion.

\section{Conclusions}

Findings from this study showed low urinary potassium excretion among respondents which indicates low dietary potassium intake among the adults in Malaysia. Malay adults and females have recorded lower potassium intake in their respective group of analysis. Although potassium intake was not significantly associated with blood pressure in this study, the results from the regression analysis supports potassium's protective role in blood pressure control. Therefore, the general population in the country need to be educated and encouraged to consume food rich in potassium, particularly fresh fruits and vegetables in their daily diet to maximize the benefits of potassium intake for health. Relevant government agencies should consider providing subsidies in the forms of price control or income assistance to ease the burden of the middle- and lowincome groups in purchasing fruits and vegetables.

\section{Abbreviations}

MyCoSS: Malaysian Community Salt Survey; RNI: Recommended Nutrient Intake; WHO: World Health Organization; NHMS: National Health and Morbidity Survey; IOM: Institute of Medicine; NHANES: National Health and Nutrition Examination Survey; PURE: Prospective Urban and Rural Epidemiological Study; BMI: Body mass index; SD: Standard Deviation; SPSS: Statistical Package for the Social Sciences; Cl: Confidence interval; MDG: Malaysian Dietary Guideline

\section{Acknowledgements \\ The authors would like to acknowledge the Director General of Health Malaysia for permission to publish this paper. Appreciation goes to the Department of Statistics, Malaysia in the sampling process. \\ Acknowledgement also goes to Ministry of Health Malaysia (Nutrition Division, Non-Communicable Disease Section, State Health Departments, Li- aison Officers and Scouts) in the preparation and during the data collection. Our sincere appreciation also goes to all participants and data collectors.}

\section{About this supplement}

This article has been published as part of Journal of Health, Population and Nutrition Volume 40 Supplement 1, 2021: Malaysian Community Salt Survey 2017-2018 (MyCoSS). The full contents of the supplement are available online at https://jhpn.biomedcentral.com/articles/supplements/volume-40supplement-1.

\section{Authors' contributions}

RA, FO, LP, RS, NSAA, AB, and NAMZ were responsible for the concept and project development. RA, FO, and RS supervised the project's progress. LP analyzed the data and constructed the draft manuscript. All authors contributed to the preparation of the manuscript, reviewing and approving the final manuscript

\section{Funding}

Publication costs are funded by the Newton-Ungku Omar Fund: United Kingdom-Malaysia Bilateral Health Research Collaboration for NonCommunicable Diseases with the grant number of MR/P012590/1 (joint funding from the Academy of Sciences Malaysia, Malaysian IndustryGovernment Group for High Technology, and the Medical Research Council, UK). The funders had no role in the study design, data collection, data analysis, data interpretation, or writing of the article.

\section{Availability of data and materials}

The datasets used and/or analyzed during the current study are available from the corresponding author on reasonable requests.

\section{Declarations}

Ethics approval and consent to participate

Ethical approvals for the study were obtained from the Medical Research Ethics Committee (MREC), Ministry of Health Malaysia (NMRR-17-423-34969) and Queen Mary (University of London) Research Ethics Committee (QMER C2017/14) prior to conducting the study. Every respondent who agreed to participate in this study and met the eligibility criteria were provided information sheet that explained the purpose and detailed information of the study and signed the consent form.

Consent for publication

Not applicable.

Competing interests

The authors declare that they have no competing interests. 


\section{Author details}

Institute for Public Health, National Institutes of Health, Ministry of Health Malaysia, Selangor, Malaysia. ${ }^{2}$ Department of Dietetic and Food Service, Sarawak General Hospital, Ministry of Health Malaysia, Kuching, Sarawak, Malaysia.

Published: 31 May 2021

\section{References}

1. World Health Organization. A Global Brief on Hypertension - World Health Day 2013. Geneva: WHO Press; 2013. p. 1-40.

2. Institute for Public Health. National Health and Morbidity Survey 2015. Vol. II: Non-communicable diseases, risk factors \& other health problems. Ministry of Health, Malaysia. 2015;1-291.

3. World Health Organization. Global Atlas on Cardiovascular Disease Prevention and Control. Geneva: WHO Press; 2011. p. 1-156.

4. American Heart Association. What is High Blood Pressure? Available from: https://www.heart.org/-/media/files/health-topics/answers-by-heart/what-ishigh-blood-pressure.pdf?la=en. Accessed 14 Nov 2019.

5. Martin TP, Fischer AN. Sodium, potassium and high blood pressure. ACSM's Health Fitness J. 2012;16(3):13-21.

6. He FJ, MacGregor GA. Beneficial effects of potassium on human health. Physiol Plant. 2008 Aug;133(4):725-35.

7. Palmer BF, Clegg DJ. Physiology and pathophysiology of potassium homeostasis. Adv Physiol Educ. 2016;40(4):480-90.

8. Yang Q. Sodium and potassium intake and mortality among US adults. Arch Intern Med. 2011;171(13):1183.

9. Aburto NJ, Hanson S, Gutierrez H, Hooper L, Elliott P, Cappuccio FP. Effect of increased potassium intake on cardiovascular risk factors and disease: systematic review and meta-analyses. BMJ. 2013;346(apr03-3): f1378.

10. Park Y, Kwock C, Kim K, Kim J, Yang Y. Interaction between single nucleotide polymorphism and urinary sodium, potassium, and sodiumpotassium ratio on the risk of hypertension in Korean adults. Nutrients. 2017;9(3):235.

11. World Health Organization. Guideline: Potassium Intake for Adults and Children. Geneva: WHO Press; 2012. p. 1-46.

12. National Coordinating Committee on Food and Nutrition (NCCFN). Recommended Nutrient Intakes for Malaysia. Ministry of Health. Malaysia. 2017:2017.

13. IOM. Dietary Reference Intake: The Essential Guide to Nutrient Requirements. Washington, DC: The National Academies Press. 2011.

14. Nohara-Shitama $Y$, Adachi $H$, Enomoto M, Fukami A, Kumagai E, Nakamura $S$, et al. Twenty-four-hour urinary potassium excretion, but not sodium excretion, is associated with all-cause mortality in a general population. J Am Heart Assoc. 2018;7:e007369.

15. Molina MCB, Pereira TSS, Porto AS, Silva RP, Santana NMT, Cade NV, et al. Validation of single measurement of 12-hour urine excretion for estimation of sodium and potassium intake. A longitudinal study. Sao Paulo Med J. 2018;136(2):150-6.

16. Majid HA, Ramli L, Ying SP, Su TT, Jalaludin MY. Dietary intake among adolescents in a middle-income country: An outcome from the Malaysian health and adolescents longitudinal research team study (The MyHearts study). PLoS One. 2016;11(5):1-14.

17. Chen X, Guo X, Ma J, Zhang J, Tang J, Yan L, et al. Urinary sodium or potassium excretion and blood pressure in adults of Shandong province, China: Preliminary results of the SMASH project. J Am Soc Hypertens. 2015; 9(10):754-62.

18. Yin L, Deng G, Mente A, Sun Y, Liu X, Zhang X, et al. Association patterns of urinary sodium, potassium, and their ratio with blood pressure across various levels of salt-diet regions in China. Sci Rep. 2018;8(1):1-11.

19. Kieneker LM, Gansevoort RT, de Boer RA, Brouwers FP, Feskens EJM, Geleijnse JM, et al. Urinary potassium excretion and risk of cardiovascular events. Am J Clin Nutr. 2016;103(5):1204-12.

20. Zhang Z, Cogswell ME, Gillespie C, Fang J, Loustalot F, Dai S, et al. Association between usual sodium and potassium intake and blood pressure and hypertension among U.S. adults: NHANES 2005-2010. PLoS One. 2013;8(10):e75289.

21. Burtis CA, Ashwood ER. Tietz Textbook of Clinical Chemistry. 2nd ed. Philadelphia: WB Saunders; 1994. p. 790-1.
22. O'Donnell M, Mente A, Rangarajan S, McQueen MJ, Wang X, Liu L, et al. Urinary sodium and potassium excretion, mortality, and cardiovascular events. N Engl J Med. 2014;371(7):612-23.

23. Cogswell ME, Loria CM, Terry AL, Zhao L, Wang CY, Chen TC, et al. Estimated 24-hour urinary sodium and potassium excretion in US Adults. J Am Med Assoc. 2018;319(12):1209-20.

24. Donfrancesco C, Ippolito R, Lo Noce C, Palmieri L, lacone R, Russo O, et al. Excess dietary sodium and inadequate potassium intake in Italy: Results of the MINISAL study. Nutr Metab Cardiovasc Dis. 2013;23(9):850-6.

25. Mizéhoun-Adissoda C, Houinato D, Houehanou C, Chianea T, Dalmay F, Bigot A, et al. Dietary sodium and potassium intakes: Data from urban and rural areas. Nutrition. 2017;33:35-41.

26. Miyagawa N, Okuda N, Nakagawa H, Takezaki T, Nishi N, Takashima N, et al. Socioeconomic status associated with urinary sodium and potassium excretion in Japan: NIPPON DATA 2010. J Epidemiol. 2018;28(Suppl 3):S2934

27. Mirzaei M, Soltani M, Namayandeh M, GharahiGhehi N. Sodium and potassium intake of urban dwellers in Yazd-Iran. J Health Popul Nutr 2014: 32(1):111-117.

28. D'Elia L, Brajovic M, Klisic A, Breda J, Jewell J, Cadjenovic V, et al. Sodium and potassium intake, knowledge attitudes and behaviour towards salt consumption amongst adults in Podgorica, Montenegro. Nutrients. 2019;11: 160.

29. Aris T, Zainuddin AA, Ahmad NA, Kaur J. National Health and Morbidity Survey 2014:Malaysian Adult Nutrition Survey (MANS): Vol. 2. Institute for Public Health. Malaysia: Ministry of Health; 2014. p. 259-62.

30. Weaver CM. Potassium and health. Adv. Nutr. 2013;4:3685-775.

31. Mente A, Dagenais G, Wielgosz A, Lear SA, McQueen MJ, Zeidler J, et al. Assessment of dietary sodium and potassium in Canadians using 24-hour urinary collection. Can J Cardiol. 2016;32(3):319-26.

\section{Publisher's Note}

Springer Nature remains neutral with regard to jurisdictional claims in published maps and institutional affiliations.

Ready to submit your research? Choose BMC and benefit from:

- fast, convenient online submission

- thorough peer review by experienced researchers in your field

- rapid publication on acceptance

- support for research data, including large and complex data types

- gold Open Access which fosters wider collaboration and increased citations

- maximum visibility for your research: over $100 \mathrm{M}$ website views per year

At BMC, research is always in progress.

Learn more biomedcentral.com/submissions 